ROVIRA, V. DELTORO, J. PÉREZ BOTELLA, A. OlIVARES, B. PÉREZ ROCHER, M. C. ESCRIBÁ, J. BENITO AYUSO -2000Adiciones y correcciones a la orquidoflora Valenciana, I. Flora Montiberica 15: 10-20.

TYTECA, D. \& M. DUFRÊNE -1994- Biostatistical studies on Western European allogamous populations of the Epipactis helleborine (L.) Crantz species group (Orchidaceae). Systematic Botany 19: 424-442.

TYTECA, D. - 1997- The Orchid Flora of Portugal. Jour. Eur. Orch. 29: 185-581.
TYTECA, D. -2000- The Orchid Flora of PortugalAddendum N.3- Remarks on Spiranthes spiralis (L.) Chevall, and three new taxa to the Portuguese Flora. Jour. Eur. Orch. 32: 291347.

Aceptado para su publicación en Julio de 2000

Address of author. School House, Brancepeth, Durham DH7 8DG United Kingdom. e-mail: MichaeIRLowe@orchid.freeserve.co.uk

\title{
71. NOVEDADES COROLÓGICAS PARA LA FLORA DE LA PROVINCIA DE CÓRDOBA
}

\author{
Javier QUIJADA, Antonio J. SÁNCHEZ ALMENDRO, \\ Jesús M. MUÑOZ ÁLVAREZ y Emilio RUIZ DE CLAVIJO
}

New floristic records for the flora of Cordoba.

Palabras clave. Corología, Córdoba, Andalucía Occidental, España.

Key words. Chorology, Córdoba, Western Andalusia, Spain.

Se aportan nuevas localidades de interés corológico para la provincia de Córdoba, relativas a un total de 15 taxones. Parte de las mismas proceden del Parque Natural de la Sierra de Cardeña y Montoro. Este espacio protegido posee una superficie de 41.212 hectáreas y se encuentra en el extremo nororiental de la provincia, límítrofe con la de Jaén. La mayor parte de su superficie pertenece a la comarca Pedroches, aunque la banda más meridional forma parte ya de la comarca Sierra Norte.

Para cada taxón se indica la distribución previamente conocida en Andalucía Occidental

Estudio financiado parcialmente por la Consejería de Medio Ambiente de la Junta de Andalucía, Proyecto de Investigación: «Cartografía y Evaluación de la Vegetación del Parque Natural de la Sierra de Cardeña y Montoro". 
de acuerdo con la Flora Vascular de Andalucía Occidental (Valdés et al., 1987), así como, siempre que ha sido posible, los sintaxones en los que se ha encontrado.

El material herborizado se encuentra depositado en el herbario del Departamento de Biología Vegetal, División de Botánica, de la Facultad de Ciencias de Córdoba (COFC).

Eschscholzia californica Cham. in C.G. Nees, Horae Phys. Berol. 74 (1820)

Especie naturalizada de origen norteamericano citada para Andalucía Occidental sólo en la comarca del Litoral (Valdés, 1987). La presente cita constituye la primera para la provincia de Córdoba y la comarca Sierra Norte (Santa María de Trassierra, bajada al río Guadiato, bordes de la carretera, UH30, 4-V-95, Salas, COFC 27117).

Fumaria muralis Sonder ex Koch, Syn. Fl. Germ., ed. 2, 1017 (1845)

Primera cita para la comarca Pedroches. Se conocía de las comarcas Sierra Norte, Aracena y Andévalo (Valdés, 1987). Se ha encontrado en comunidades terofíticas escionitrófilas asociadas a matorrales preforestales. (Montoro, Coto Españoletos, caídas al arroyo Martín-Gonzalo, 555 $\mathrm{m}$, UH-82, 11-V-98, Muñoz \& Quijada, COFC 26758).

\section{Salsola kali L,. Sp. Pl. 222 (1753) subsp kali}

Primera cita de esta especie para la provincia de Córdoba. El área de distribución indicada en la Flora Vascular de Andalucía Occidental comprendía las comarcas del Litoral y Algeciras (Pastor, 1987). Posteriormente su presencia fue indicada en la Campiña sevillana por Albareal \& Romero Zarco (1993). Su área de distribución hay que ampliarla a la comarca de Los Pedroches. (Hinojosa del Duque, alrededores, UH-16, 15-V-99, Rojas, COFC 27118).

Chaetonychia cymosa (L.) Sweet, Hort. Brit., ed. 3: 263 (1839)

Primera cita de este taxón para la comarca Pedroches. Devesa (1987) indicó su presencia en Sierra Norte sevillana, Aracena, Andévalo, Campiña de Huelva, Condado-Aljarafe, Litoral, Campiña Baja gaditana y Algeciras y, posteriormente, Jiménez \&
Ruíz de Clavijo (1990) lo citaron para Zújar. Se ha herborizado en pastizales terofíticos pioneros de escasa cobertura sobre cuarcitas. (Montoro, Coto El Socor, 770 m, UH-92, 24-V-99, Muñoz \& Sánchez, COFC 26665).

\section{Cistus laurifolius L., Sp.Pl .523 (1753)}

Primera cita para Córdoba y la comarca Pedroches y segunda para Andalucía Occidental. En 1991 Cepeda cita por primera vez esta especie para Andalucía Occidental de una localidad de la comarca Sierra Norte, en Sevilla (aunque previamente existía una cita antigua para Córdoba, de Colmeiro (1885)). Se ha herborizado en una comunidad seminatural, de origen antrópico: una ladera arbolada de $Q$. rotundifolia Lam., con fuerte pendiente $(65 \%)$ y estrato arbustivo de escasa cobertura $(40 \%)$, con $Q$. coccifera L. y $Q$. rotundifolia Lam. como especies más abundantes; sobre pizarras. Pocos individuos y en estado crítico. (Cardeña, Coto Volteones, 530 m, UH-94, 17-6-99, Muñoz \& Sánchez, COFC 27107).

Aphanes floribunda (Murb.) Rothm., Repert. Spec. Nov. Regni Veg. 42: 172 (1937)

Nueva cita para la comarca Pedroches. Se encontraba citado para Sierra Norte, Vega y Grazalema (Devesa, 1987). Se ha encontrado en comunidades terofíticas enriquecidas en especies subnitrófilas. (Cardeña, Coto el Aguila, $710 \mathrm{~m}$, UH83, 3-III-98, Muñoz \& Quijada, COFC 27087).

\section{Cicer arietinum L., Sp. Pl. 738 (1753)}

Especie cultivada no recogida en la Flora Vascular de Andalucía Occidental de la que se ha encontrado una población asilvestrada en las estribaciones de la Sierra Norte cordobesa, procedente quizás, de antiguos cultivos desaparecidos hace años. (Córdoba, entre Córdoba y Santa María de Trassierra, castillo de la Albaida, bordes de la carretera, UG-39, 9-III-98, Ruiz de Clavijo, COFC 27119).

\section{Ornithopus perpusillus L., Sp. Pl. 743 (1753)}

Novedad corológica para la flora de Andalucía Occidental. Ha sido localizada en la comarca de Los Pedroches formando parte de pastizales efímeros sobre suelos ácidos. (Santa Eufemia, Sierra de Santa Eufemia, cerro del Telégrafo, UG-39, 13-V-93, Velasco, COFC 27120). 
Turgenia latifolia (L.) Hoffm., Gen. Umb. 59 (1814)

Una nueva localidad para esta especie no recogida en la Flora Vascular de Andalucía Occidental. Ha sido localizada próxima a la indicada por García Montoya \& Muñoz (1990) en la Campiña Alta cordobesa confirmándose así su presencia en la provincia de Córdoba. (Luque, alrededores de la laguna del Salobral, UG-95, 11 -V-96, López, COFC 27121).

\section{Asperugo procumbens L., Sp. Pl. 138 (1753)}

Especie no recogida en la Flora Vascular de Andalucía Occidental de la que se conocen algunas citas antiguas en las provincias de Sevilla y Córdoba, y sólo una reciente en la Campiña Alta cordobesa (García Montoya \& Muñoz, 1990). Posteriormente ha vuelto a ser recolectada en la Subbética cordobesa (Cabra, Parque Natural de la Subbética, UG-85, 17 V-91, Domínguez, Muñoz \& Ruiz de Clavijo, COFC 27122).

\section{Sambucus nigra L., Sp. Pl. 269 (1753)}

Primera cita para la comarca Sierra Norte en la provincia de Córdoba. García Martín (1987) indicó su presencia en Aracena, Subbética, Grazalema y Algeciras. Posteriormente Sánchez García \& Martínez Ortega (1994) la indicaron para la Campiña Baja gaditana, y Morales \& al. (1997) para la Sierra Norte sevillana (Córdoba, alrededores de Obejo, UH-42, 4-VI-91, Galán \& Ruiz de Clavijo, COFC 27123).

\section{Juncus foliosus Desf., Fl. Atl. 1: 315 (1798)}

Primera cita para la provincia de Córdoba y la comarca Sierra Norte. Se encontraba citado únicamente para las comarcas Aracena, Litoral y Algeciras (partes bajas) (Fernández-Carvajal, 1987). Se ha herborizado en una comunidad de helófitos decumbentes, en aguas superficiales de estiaje acusado. (Montoro, Coto Españares, arroyo del Robledillo, 395 m, UH-82, 4-V-98, Muñoz \& Quijada, COFC 27082).

Luzula forsteri (Sm.) DC. in Lam. \& DC., Syn.Pl. Fl. Gall.150 (1806)

Primera cita de este taxón para la provincia de Córdoba. Su areal en Andalucía Occidental abarcaba las comarcas Aracena, Grazalema y Algeciras (Valdés, 1987) y Sierra Norte sevillana (Morales \& al., 1998). Se ha encontrado en el estrato herbáceo de una fresneda, en la comarca Sierra Norte. (Montoro, Coto Los Rasos, 345 m, UH-82, 09-VI99, Muñoz \& Sánchez, COFC 26748).

Corynephorus divaricatus (Pourret) Breistr., Procés-Verb. Soc. Dauph. Étud. Biol. (Grenoble), ser. 3, 17: 3 (1950) subsp. macrantherus (Boiss. \& Reuter) Paunero, Anales Inst. Bot. Cavanilles 13: 168 (1955)

Taxón raro en Andalucía Occidental, conocido únicamente del Litoral gaditano (Romero Zarco, 1987) y Campiña Baja sevillana (Roales, 1999). Esta constituye pues la primera cita para la provincia de Córdoba y para la comarca Pedroches. Se ha localizado en comunidades terofíticas de escasa cobertura, en claros de un cantuesal; sobre arenosoles graníticos, en la llanura de inundación del Río Yeguas. (Cardeña, Coto Alamedilla Baja, Río Yeguas, $400 \mathrm{~m}$, UH-93, 11-VI-98, Muñoz \& Quijada COFC 27065).

Agrostis tenerrima Trin., Gram. Unifl. 205 (1824)

Novedad corológica para la comarca Pedroches. Su areal en Andalucía Occidental se extendía por las comarcas Aracena, Andévalo, Campiña de Huelva, Litoral, Grazalema y Algeciras (Romero Zarco, 1987), Zújar (Jiménez \& Ruíz de Clavijo, 1990) y Sierra Norte cordobesa (Pinilla \& al., 1998). Se ha herborizado en comunidades terofíticas de poca cobertura $(50 \%)$ y pobres en especies (en su mayoría de Helianthemetalia guttati). (Montoro, Coto El Socor, 765 m, UH-92, 24-V-99, Muñoz \& Sánchez, COFC 26824).

\section{BIBLIOGRAFÍA}

ALBAREAL, J y C. ROMERO ZARCO -1993Notas taxonómicas y corológicas para la flora vascular de Andalucía y del Rif. 26. Novedades florísticas para la Campiña y las Sierras Subbéticas sevillanas, Lagascalia 17: 190-193. CEPEDA, J.M. -1991- Cistus laurifolius L. (CISTACEAE), Nueva especie para la Flora de Andalucía Occidental. Anales del Jardín Botánico de Madrid 49: 139.

COLMEIRO, M. -1885-Enumeración y Revisión de Plantas de la Península Hispano-Lusitana e Islas Baleares. Tomo I. Madrid. 
DEVESA, J.A. - 1987- Cheaetonychia, Aphanes, in B. VALDÉS et al. (eds.) Flora Vascular de Andalucia Occidental 1:210, 2:37-38. Editorial Ketres. Barcelona.

FERNÁNDEZ CARVAJAL, M.C. -1987- Juncus in B. VALDÉS et al. (eds.) Flora Vascular de Andalucía Occidental 3: 213-228. Editorial Ketres. Barcelona.

GARCÍA MARTÍN, F. -1977- Sambucus in B.VALDÉS et al. (eds.) Flora Vascular de Andalucia Occidental 2: 595-596. Editorial Ketres. Barcelona.

GARCÍA MONTOYA, F y J.M. MUÑOZ -1990Notas taxonómicas y corológicas para la flora vascular de Andalucía y del Rif. 18. Novedades corológicas para la flora de Andalucía Occidental. Lagascalia 16: 146-168.

JIMÉNEZ, M. y E. RUÍZ DE CLAVIJO -1990Notas taxonómicas y corológicas para la flora vascular de Andalucía y del Rif. 16. Nuevas áreas para la Flora de Andalucía Occidental. Lagascalia 16: 132-145.

MORALES, M., J.M. DELGADO, R. TAMAJÓN, A. TORRECILLA y J.M. MUÑOZ-1997- Notas Taxonómicas y Corológicas para la Flora Vascular de Andalucía y del Rif. 57. Novedades corológicas para la comarca de Sierra Norte en la Provincia de Sevilla. Lagascalia 20: 316330.

PASTOR, J. -1987- Salsola in B. VALDÉS et al. (eds.) Flora Vascular de Andalucía Occidental 1: 190-193. Editorial Ketres. Barcelona.

PINILLA, R., R. TAMAJÓN y J. MUÑOZ -1998Aportaciones a la flora de Córdoba. Acta Bot. Malacitana 23: 260-269.

ROALES, J.-1999- Contribución al conocimiento de la Flora de Sevilla. III: novedades corológicas comarcales. Lagascalia 21: 61-110.

ROMERO ZARCO, C. -1987- Corynephorus, Agrostis, in B. VALDÉS \& al. (eds.) Flora Vascular de Andalucía Occidental 3: 333-335, 336-341. Editorial Ketres. Barcelona.

SÁNCHEZ GARCÍA, I. y C. MARTÍNEZ ORTEGA -1994- Notas taxonómicas y corológicas para la flora vascular de Andalucía y del Rif. 30. Nuevas áreas para la flora de Andalucía Occidental. Lagascalia 17: 357-366.

VALDÉS, B -1987- Eschscholzia, Fumaria, Luzula, in B. VALDÉS et al. (eds.) Flora Vascular de Andalucía Occidental 1: 135; 140-147, 3: 228.
Editorial Ketres. Barcelona.

VALDÉS, B., S. TALAVERA y E. FERNÁNDEZ-

GALIANO (eds.) -1987- Flora Vascular de Andalucía Occidental. 3 vols. Editorial Ketres. Barcelona.

Aceptado para su publicación en julio de 2000

Dirección de los autores. Departamento de Biología Vegetal, División de Botánica, Facultad de Ciencias, Universidad de Córdoba. Campus de Rabanales, Colonia de San José N ${ }^{\circ} 4$, 14071-Córdoba 